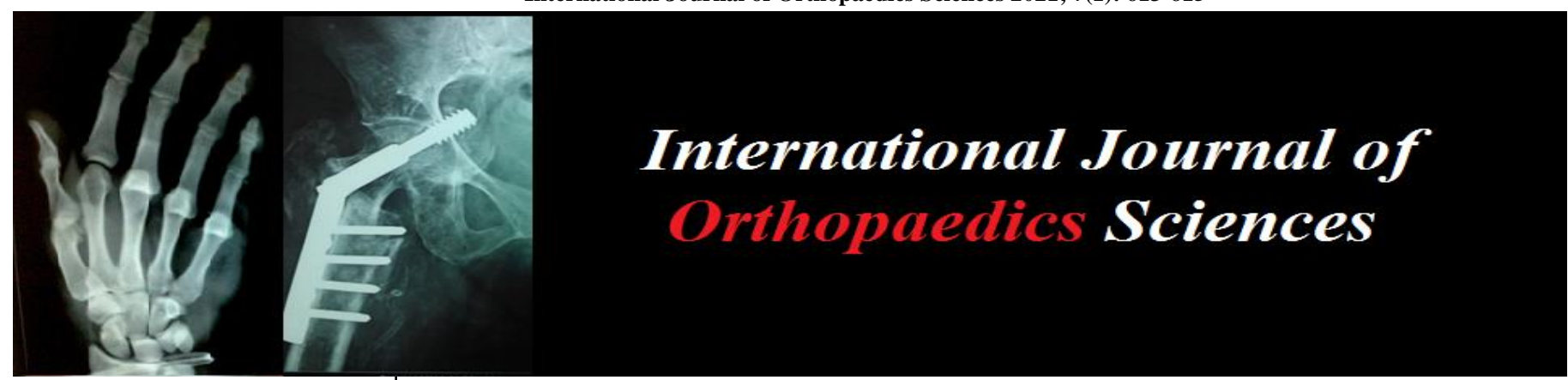

E-ISSN: 2395-1958

P-ISSN: 2706-6630

IJOS 2021; 7(1): 613-615

(C) 2021 IJOS

www.orthopaper.com

Received: 19-11-2020

Accepted: 21-12-2020

Dr. Tejus DB

MBBS, MS Orthopaedics,

Consultant Orthopaedic Surgeon,

JSS Hospital, Chamrajnagar,

Karnataka, India

Dr. Avinash Chandra

MBBS, Junior Resident,

Department of Orthopaedics,

JSS Hospital, Chamrajanagar,

Karnataka, India

Corresponding Author:

Dr. Tejus DB

MBBS, MS Orthopaedics,

Consultant Orthopaedic Surgeon,

JSS Hospital, Chamrajnagar,

Karnataka, India

\section{Reichel syndrome of knee joint: A rare case report}

\section{Dr. Tejus DB and Dr. Avinash Chandra}

DOI: https://doi.org/10.22271/ortho.2021.v7.i1j.2549

\section{Abstract}

Reichel syndrome (primary synovial chondrometaplasia of a joint) is a rare condition seen in patients. Patients present with significant symptoms which can affect their normal routine life. Early diagnosis and surgical management will improve the quality of life of patient.

Keywords: reichel syndrome, primary synovial chondromatosis, loose bodies, knee stiffness, swelling, restricted ROM

\section{Introduction}

Reichel syndrome / primary synovial condromatosis / primary synovial chondrometaplasia is a rare disease, usually affecting monoarticular joints ${ }^{[1]}$. Usually being benign disorder has a rare chance for malignant transformation ${ }^{[2]}$. Knee joint is the most common joint affected. However, synovial chondromatosis can affect any synovial joint (hip, elbow, shoulder, temporal mandibular joint, and ankle may also be affected) ${ }^{[3]}$. A rare occurrence is an extraarticular presentation in synovial lined bursal tissue or tenosynovium in which the typical chondral loose bodies form. These are referred to as tenosynovial chondromatosis or bursal chondromatosis ${ }^{[3]}$. Management of primary synovial chondromatosis is surgery by excision of bony lesion and total synovectomy or arthroscopic removal if loose bodies are small ${ }^{[4]}$. Post-operative management includes a progressive range of motion and strengthening of peri-articular muscle groups ${ }^{[5]}$.

\section{Case discussion}

A 38 year old male, farmer by occupation presented with chief complaint pain, swelling, restriction in ROM of left knee joint since 2 years. There was no history of trauma, infection, metabolic disorder, no similar swellings in the other joints, congenital disorder. On local examination, patient had antalgic gait. Swelling around the superior, medial \& lateral borders of patella. Consistency of the swelling was stony hard. Patellar tap was positive. Active ROM of left knee joint $160^{-100}$. No FFD of left knee joint was appreciated. No distal neurovascular deficiency was observed.

X-ray \& MRI of the knee joint was advised with blood investigations. ESR CRP IL6 were high.

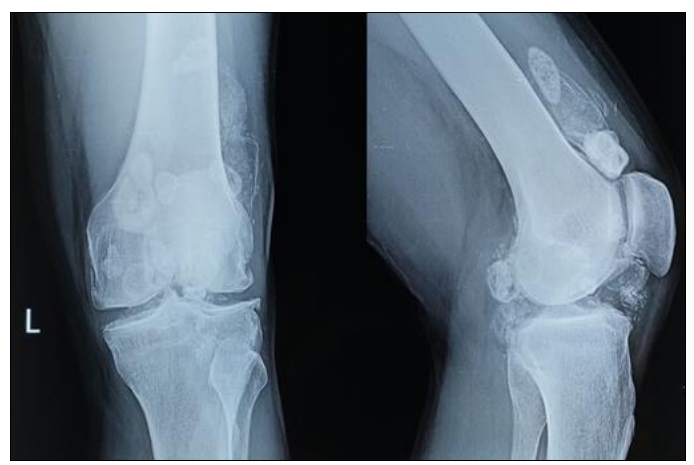

Fig 1: X-ray depicting extra \& intra-articular bony lesions

$$
\sim 613 \sim
$$



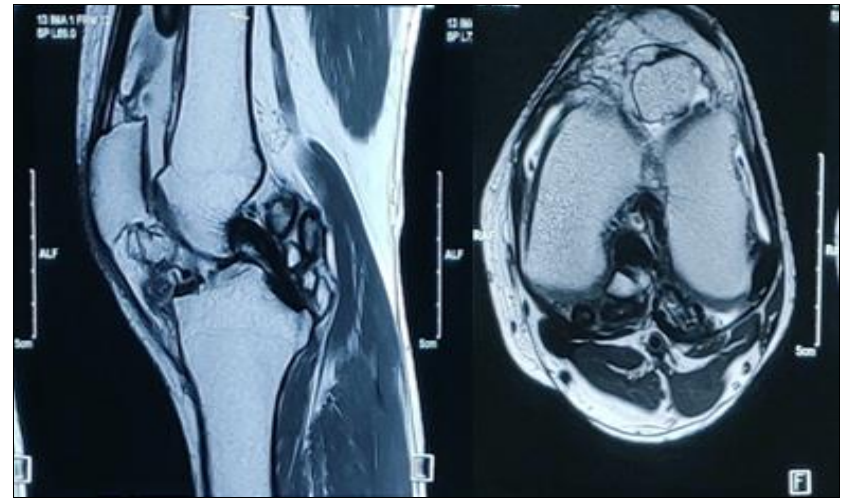

The patient was counselled regarding the need of surgeryOpen total synovectomy \& removal of loose bodies as arthroscopic removal of large synovial bodies was not feasible. After preoperative blood workup \& with patients consent, he was taken up for surgery.

Through medial parapatellar approach, the knee joint was exposed. Multiple Loose bodies ranging from $0.5 \mathrm{~cm}-6 \mathrm{~cm}$ were removed in parapatellar, suprapatellar, posterior aspect of left knee joint. This was followed by total synovectomy \& were sent to histopathological examination. After a sterile wash wound was closed in layers. The patient was advised for active knee physiotherapy exercises after the surgery.

Fig 2: MRI of the left knee joint

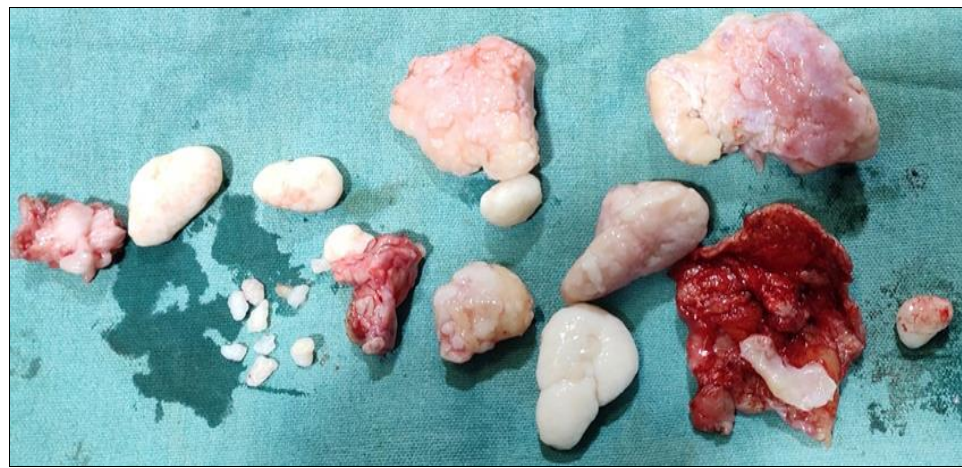

Fig 3: Image depicting the loose bodies \& synovial tissue removed from the knee joint.
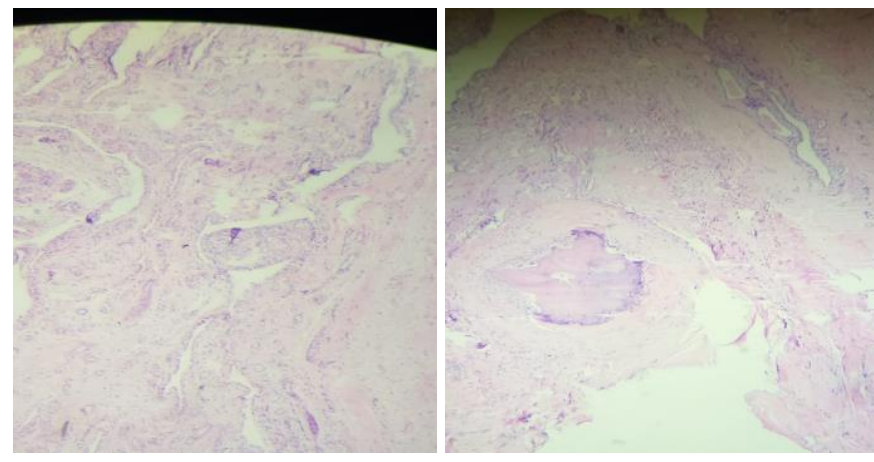

Fig 4: Histopathology showing synovial hyperplasia on the left \& synovial cartilage on right.

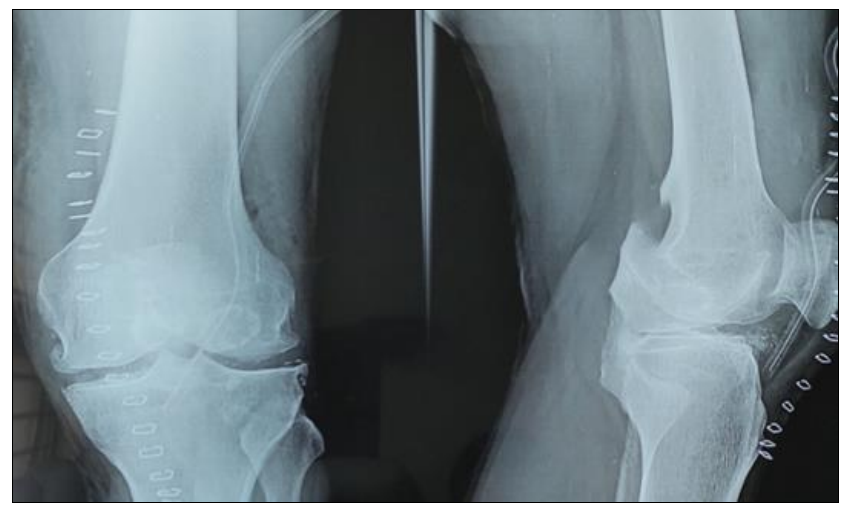

Fig 5: Postoperative X-ray

All the loose bodies removed depicted in this xray.

\section{Discussion}

Synovial chondrometaplasia is characterized by the formation of intra-articular nodules of the synovium that can detach and become loose bodies, which can secondarily become calcified /ossified ${ }^{[4,6]}$. The differential diagnosis associated with SC should include synovial hemangioma, pigmented villonodular synovitis, synovial cyst, lipoma arborescence, and malignancies, such as synovial chondrosarcoma or synovial sarcoma ${ }^{[3]}$ Synovial chondromatosis canmimic osteoarthritis or meniscal pathology ${ }^{[3]}$. Because of a chance of malignant transformation, any patient with rapid late deterioration of clinical features should be evaluated for chondrosarcoma or synovial sarcoma ${ }^{[1-4]}$. Plain radiographs may help differentiate the cause showing calcific joint mice and periarticular erosions. However, the intra-articular loose bodies are frequently radiolucent, and a MRI may be warranted to definitively differenti- ate the diagnosis [2, 7, 8]. A classic article by Milgram discussed the phases of the proliferative changes associated with $\mathrm{SC}$, where phase 1 shows active intrasynovial disease with no loose bodies.9 Phase 2 has transitional lesions with osteochondral nodules within the synovial membrane and free bodies within the joint cavity. Last, in phase 3 , there are multiple osteochondral free bodies but quiescent intrasynovial disease. There is a controversy whether arthroscopic removal of loose bodies or excision with synovectomy is the treatment of choice ${ }^{[6]}$. Ogilvie-Harris and colleagues reviewed the results of both procedures and found that although removal of loose bodies alone may be sufficient, there is the potential for recurrence ${ }^{[9,10]}$. In order to reduce potential recurrence, Removal of loose bodies with anterior and posterior synovectomy is the treatment of choice ${ }^{[9]}$.

Unfortunately, osteoarthritis can be a significant long-term postoperative adverse effect ${ }^{[3,6-8]}$. This typically is related to the amount of articular damage that is present at surgery. Many times, the arthritis becomes significant enough to require total joint arthroplasty. Close long term follow-up is recommended, because although rare, there is a chance of malignant change. 


\section{Conclusion}

Reichel syndrome, being a very very rare condition often presents with a challenging scenario to Orthopaedic surgeon. Though benign in its nature, the symptoms can be severe in the patients. So early diagnosis with open surgical management yields a good result in the functional outcome of the patient.

On behalf of all the authors, there is no conflict of interest.

\section{References}

1. [Reichel syndrome. A case report with review of the literature] A Kotter 1, E Mayr, K Kundel, A Rüter

2. Synovial Chondromatosis Steven F. Habusta; Joshua A. Tuck

3. Synovial Chondromatosis: An Unusual Case of Knee Pain and Swelling. Melissa Moates Grace, MSN, RN; Lt Col (Ret) Eric J. Letonoff, DO

4. Libbey NP, Mirrer F. Synovial chondromatosis. Med Health R I. 2011;94(9):274-275.

5. Giancane G, Tanturri de Horatio L, Buonuomo PS, Barbuti D, Lais G, Cortis E. Swollen knee due to primary synovial chondromatosis in pediatrics: a rare and possibly misdiagnosed condition. Rheumatol Int 2013;33(8):21832185.

6. Serbest S, Tiftikçi U, Karaaslan F, Tosun HB, Sevinç HF, Balci M. A neglected case of giant synovial chondromatosis in knee joint. Pan Afr Med J 2015;22:5.

7. Hallam P, Ashwood N, Cobb J, Fazal A, Heatley W. Malignant transformation in synovial chondromatosis of the knee? Knee 2001;8(3):239-242.

8. Pimentel Cde Q, Hoff LS, de Sousa LF, Cordeiro RA, Pereira RM. Primary synovial osteochondromatosis of the knee. Rheumatol (Oxford) 2015;54(10):1815.

9. Damron TA, Sim FH. Soft-tissue tumors about the knee. J Am Acad Orthop Surg 1997;5(3):141-152.

10. Krych A, Odland A, Rose P et al. Onconlogic conditions that simulate common sports injuries. J Am Acad Orthop Surg 2014;22(4):223-234.

11. Adelani MA, Wupperman RM, Holt GE. Benign synovial disorders. J Am Acad Orthop Surg 2008;16(5):268-275

12. Migram JW. Synovial osteochondromatosis: a histopathological study of thirty cases. J Bone Joint Surg Am 1977;59(6):792-801.

13. Ogilvie-Harris DJ, Saleh K. Generalized synovial chondromatosis of the knee: a comparison of removal of the loose bodies alone with arthroscopic synovectomy. Arthroscopy 1994;10(2):166-170.

14. Jesalpura JP, Chung HW, Patnaik S, Choi HW, Kim JI, Nha KW. Athroscopic treatment of localized synovial chondromatosis of the posterior knee joint. Orthopedics 2010;33(1):49. 